\title{
DynamicSainT
}

Jilid. IV No. 2., Oktober 2019

\section{ANALISIS SISTEM PEMBUMIAN INSTALASI LISTRIK SATU PHASA (STUDI KELAYAKAN PADA BANGUNAN BERTINGKAT )}

\author{
Yusri Ambabunga \\ Program Studi Teknik Elektro, Fakultas Teknik, Universitas Kristen Indonesia Toraja. \\ Jl. Nusantara No. 12,Makale, Tana Toraja, Sulawesi Selatan \\ yusriambabunga@ukitoraja.ac.id
}

\begin{abstract}
ABSTRAK
Penelitian ini bertujuan untuk mengetahui macam-macam system pembumian dan faktor yang mempengaruhi pembumian serta mengetahui besarnya tahanan pembumian/impedansi pembumian pada bangunan bertingkat.. Sistem pembumian sangatlah penting untuk menyalurkan gangguan listrik satu phasa yang terjadi pada tegangan listrik nominal ke tanah, seperti hubung singkat satu phasa maupun hubung buka satu phasa yang mungkin terjadi dan berpengaruh pada peralatan - peralatan instalasi bangunan berlantai dua serta beban beban listrik satu phasa yang terpasang di dalam bangunan tersebut. Desain dan rancangan serta pemilihan bahan dan peralatan instalasi pembumian sangatlah penting, karena sangat mempengaruhi sistem keandalan, kecepatan kerja serta keamanan peralatan instalasi pembumian di dalam melindungi beban dalam daerah asuhannya (main protection) dari gangguan satu phasa yang disebabkan oleh gangguan eksternal dan internal. Sedangkan kecepatan kerja terkait dengan tingkat sensitivitas peralatan proteksi di dalam membaca dan mengukur besaran gangguan baik hubung buka (open circuit) maupun hubung singkat (short circuit) pada instalasi listrik satu phasa pada bangunan bertingkat..
\end{abstract}

Kata Kunci : Kawat pembumian, batang elektroda, peralatan proteksi gangguan (Relay).

\section{PENDAHULUAN}

Pada akhir abad ke-19 sistem tenaga listrik dibumikan. Hal ini dapat dimengerti karena pada waktu itu sistem-sistem tenaga listrik masih kecil, jadi bila ada gangguan kawat bumi arus gangguan masih kecil $( \pm 5$ A). Pada umumnya bila arus gangguan itu sebesar 5A atau lebih kecil busur listrik yang timbul pada kontak-kontak antara kawat yang terganggu dan bumi masih dapat padam sendiri (Self Extinguishng). Tetapi sistemsistem tenaga itu makin lama makin besar baik panjangnya maupuan tenaganya. Dengan demikian arus yang timbul bila terjadi lagi gejala-gejala "Arching Grounds" semakin menonjol. Gejalan ini sangat berbahaya karena akan menimbulkan tegangan lebih transient yang dapat merusak peralatan listrik dan beban.

Sistem pembumian sangatlah penting untuk menyalurkan gangguan listrik satu phasa yang terjadi pada tegangan listrik nominal ke tanah, seperti hubung singkat satu phasa yang berpengaruh pada peralatanperalatan instalasi bangunan berlantai dua serta beban beban listrik satu phasa yang terpasang di dalam bangunan tersebut.

Untuk dapat mengamankan peralatan dari berbagai gangguan yang terjadi akibat gangguan pada tegangan listrik diperlukan sistem pentanahan. Sistem pentanahan berfungsi untuk menetralkan gangguanganguan yang terjadi pada tegangan listrik seperti hubung singkat dan arus bocor pada peralatan. Yang perlu diperhatikan pada sistem pentanahan adalah tahanan jenis tanah, dan elektroda yang dipakai.

\section{METODOLOGI}

Metode penelitian yang digunakan disini, ada 2 yaitu :

1) Field Research yaitu, pengambilan data secara langsung dilapangan 


\section{DynamicSainT}

Jilid. IV No. 2., Oktober 2019

melalui proses pengukuran, adapun data data yang diperoleh adalah:

a) Nilai resistansi tanah di lokasi bangunan tersebut

b) Nilai resistansi batang elektroda sebagai alat pembumian.

c) Nilai parameter perbandingan antara tanah yang memiliki $\mathrm{PH}$ tertentu.

d) Nilai pengukuran kedalaman tanah untuk pemasangan kawat pembumian.

e) Jenis kabel dan batang elektroda untuk pembumian serta jenis kabel instalasi yang terhubung dengan kawat pembumian.

2) Library Research, yaitu pengambilan data dengan cara membaca pustaka yang memiliki relevansi dengan masalah yang terjadi di lapangan..

\section{HASIL DAN PEMBAHASAN}

Sistem Penbumian adalah suatu rangkaian atau jaringan mulai dari kutub pentanahan atau elektroda, hantaran penghubung sampai terminal pentanahan yang berfungsi untuk menyalurkan arus lebih ke bumi atau tanah dengan tujuan agar suatu peralatan dapat terhindar dari tegangan asing seperti hubung singkat atau arus bocor sehingga peralatan dapat bekerja sesuai dengan fungsi yang semestinya. Dapat dilihat pada tabel 1 .

Tabel 1. Jenis tanah yang memiliki tahanan jenis tanah

\begin{tabular}{|l|c|}
\hline \multicolumn{1}{|c|}{ Jenis Tanah } & Tahanan tanah (ohm) /m \\
\hline Sawah, Rawa & 3 \\
Tanah liat dan Tanah lading & 1 \\
Pasir basah & 2 \\
Kerikil basah & 5 \\
Pasir dan Kerikil kering & 1 \\
Tanah berbatu & 3 \\
Sumber : PLN Grounding \& Lightning Protection PT. PLN \\
(Persero) Wilayah Sulselbar
\end{tabular}

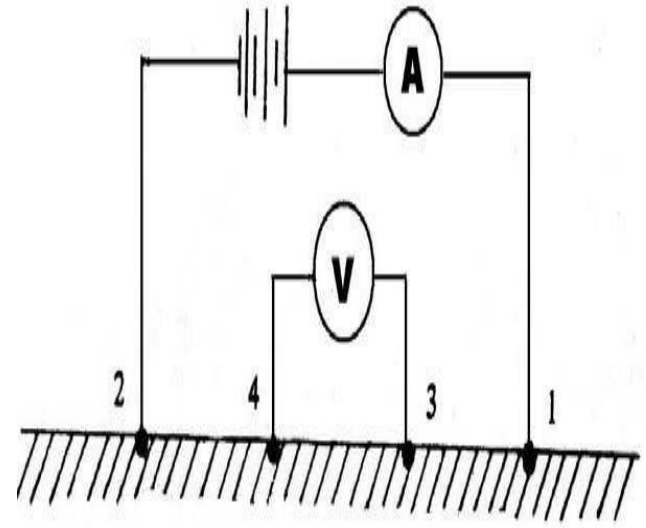

Gambar 1. Pengukuran Tahanan Jenis Tanah Metode Empat Elektroda (Four Electrode Method)
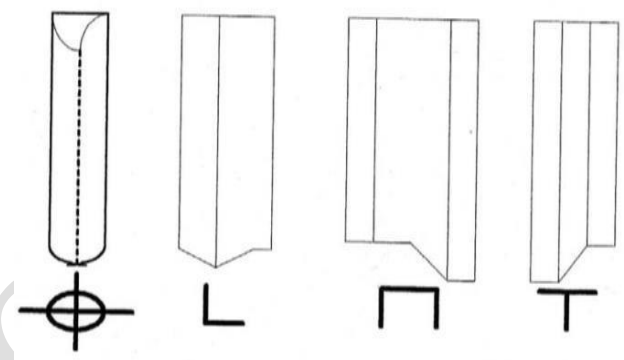

Gambar 2. Jenis batang elektroda dengan model dan ukuran dari batang elektroda

Tabel 2. Data pengukuran tahanan jenis elektroda batang

\begin{tabular}{|c|c|c|c|c|c|c|c|c|}
\hline \multirow{2}{*}{ NO } & \multicolumn{2}{|c|}{ Terminal } & \multicolumn{5}{|c|}{ Ukuran Kedalaman (m) } & \multirow{2}{*}{ Paralel } \\
\cline { 2 - 8 } & $\mathbf{E}-\mathbf{P}$ & $\mathbf{P}-\mathbf{C}$ & $\mathbf{3}$ & $\mathbf{5}$ & $\mathbf{7}$ & $\mathbf{9}$ & $\mathbf{1 2}$ & \\
\cline { 4 - 8 } & & & $\mathbf{R}(\mathbf{\Omega})$ & $\mathbf{R}(\mathbf{\Omega})$ & $\mathbf{R}(\mathbf{\Omega})$ & $\mathbf{R}(\mathbf{\Omega})$ & $\mathbf{R}(\mathbf{\Omega})$ & $\mathbf{R}(\mathbf{\Omega})$ \\
\hline 1. & 4 & 5 & 300,80 & 6,70 & 4,0 & 2,97 & 1,89 & 2,04 \\
\hline 2. & 5 & 6 & 303,90 & 6,80 & 4,1 & 2,97 & 2,01 & 2,22 \\
\hline 3. & 6 & 7 & 303,40 & 6,90 & 4,2 & 2,94 & 1,95 & 2,33 \\
\hline 4. & 7 & 8 & 303,50 & 6,90 & 4,2 & 3,01 & 1,96 & 2,28 \\
\hline 5. & 8 & 9 & 303,80 & 6,90 & 4,3 & 3,08 & 2,01 & 2,24 \\
\hline
\end{tabular}

Tabel 3. Data pengukuran tahanan jenis elektroda plat

\begin{tabular}{|c|c|c|c|c|c|c|c|c|}
\hline \multirow[t]{3}{*}{ NO } & \multicolumn{2}{|c|}{ Terminal } & \multicolumn{5}{|c|}{ Ukuran Kedalaman (m) } & \multirow{2}{*}{ Paralel } \\
\hline & E-P & P-C & 3 & 5 & 7 & 9 & 12 & \\
\hline & & & $\mathbf{R}(\Omega)$ & $\mathbf{R}(\mathbf{\Omega})$ & $R(\Omega)$ & $\mathbf{R}(\mathbf{\Omega})$ & $\mathbf{R}(\mathbf{\Omega})$ & $\mathbf{R}(\Omega)$ \\
\hline 1. & 4 & 5 & 259,00 & 6,60 & 3,90 & 2,94 & 1,87 & 2,03 \\
\hline 2. & 5 & 6 & 260,10 & 6,70 & 3,70 & 2,91 & 1,78 & 2,09 \\
\hline 3. & 6 & 7 & 260,30 & 6,90 & 3,90 & 2,98 & 1,95 & 2,21 \\
\hline 4. & 7 & 8 & 261,00 & 6,90 & 4,30 & 3,01 & 1,97 & 2,27 \\
\hline 5. & 8 & 9 & 263,80 & 7,20 & 4,70 & 3,12 & 2,30 & 2,34 \\
\hline
\end{tabular}

\section{KESIMPULAN DAN SARAN}

\subsection{Kesimpulan}




\section{DynamicSainT}

Jilid. IV No. 2., Oktober 2019

Dari hasil penelitian dan pembahasan yang telah dilakukan dapat diambil kesimpulan bahwa :

1. Pada sistem pentanahan yang ada pada Gedung betingkat minimal tingkat 2, tahanan pentanahan terukur adalah sebesar 0,82 Ohm.jadi dapat dikatakan bahwa pentanahan pada gedung tersebut memenuhi standar yaitu dibawah $5 \mathrm{Ohm}$.

2. Jenis tanah di area gedung tesebut adalah tanah liat yang mempunyai tahanan sebesar $100 \mathrm{Ohm}$.

\subsection{Saran}

1. Untuk menjaga agar nilai tahanan tetap konstan sebaiknya dilakukan pemeriksaan secara rutin atau berkala.

2. Sebaiknya elektroda tanah ditanam dengan sistem paralel sehingga tahanan pentanahan pada gedung tersebut dapat diperkecil.

\section{DAFTAR PUSTAKA}

1. Arismunandar, A, Dr 1982. Teknik Tenaga listrik, Jakarta, Jilid II, Cetakan kelima, penerbit : PT. Pardya Paramita. Harten, P. Van, 1983, Instalasi Listrk Arus kuat 3, Jakarta, edisi Ketiga, Penerbit Bima Cipta.

2. Kadir, Abdul, Prof. Ir, 1986 Transformator, Jakarta, PT. Elex Media Komputindo Gramedia. Pabla, AS, 1994, Six/em Distribusi Daya Listrik, Jakarta, Penerbit Erlangga.

3. Panangsang, O, Sutama, dan Piarsa, N, 2001, Sintulasi dan Analisis Ketidakseimbangan dan Kompensasi Daya Reaktif Pada Jaringan Distribusi, majalah IPTEK,

4. Lembaga Penelitian, Vol.12.No3,2001.

Ridwan, Nursyamsu A, 1994, "Perhitungan Susut Daya Pada Jaringan Distribusi Primer feeder 3 Pinrang". Skripsi. Makassar: 